\title{
CRESCIMENTO DE Physalis angulata L. EM SOLUÇÃO NUTRITIVA SOB PROPORÇÕES VARIÁVEIS DE AMÔNIO E NITRATO
}

\author{
$\underline{\text { Alismário Leite da Silva }}{ }^{1}$; Marilza Neves do Nascimento ${ }^{2}$; Tamara Torres Tanan ${ }^{3}$ \\ e Romeu da Silva Leite ${ }^{4}$ \\ 1. Bolsista PROBIC/CNPq, Graduando em Agronomia, Universidade Estadual de Feira de Santana, e-mail: \\ alismarioagronomo@hotmail.com \\ 2. Orientador, Departamento de Ciências Biológicas, Universidade Estadual de Feira de Santana, e-mail: \\ marilzaagro@hotmail.com \\ 3. Participante do projeto, doutoranda em Recursos Genéticos Vegetais, Departamento de Ciências Biológicas, \\ Universidade Estadual de Feira de Santana, e-mail: tamara.tanan@yahoo.com.br \\ 4. Participante do projeto, mestrando em Recursos Genéticos Vegetais, Departamento de Ciências Biológicas, \\ Universidade Estadual de Feira de Santana, e-mail: leiteromeu@ @otmail.com
}

PALAVRAS-CHAVE: adubação; nitrogênio; camapú.

\section{INTRODUÇÃO}

A espécie Physalis angulata L., conhecida popularmente na Região Nordeste por camapú ou canapú, pertence à família Solanaceae. Nativa do Brasil, é amplamente utilizada na medicina popular e fornece frutos comestíveis com alto teor de vitaminas A e $\mathrm{C}$, que além do valor nutracêutico, alia-se a facilidade de cultivo e elevado valor de mercado dos frutos, sendo excelentes atrativos para a incorporação dessa espécie pelos pequenos produtores (HARBONE \& WILLIAMS, 2000).

A adubação é um fator relevante para o aumento da produção da espécie, no entanto, pesquisas sobre este tema, para a cultura, são incipientes. Estudos que possibilitem a eficiência de absorção e utilização de nutrientes são de grande importância, pois as plantas cultivadas utilizam menos da metade dos fertilizantes aplicados. O restante pode ser lixiviado para os lençóis subterrâneos de água, tornar-se fixado ao solo ou contribuir para a poluição do ar (LACERDA et al., 2007).

$\mathrm{O}$ nitrogênio $(\mathrm{N})$ é, em geral, o elemento que as plantas necessitam em maior quantidade e o mais aplicado na agricultura. Promove modificações morfofisiológicas na planta, estando relacionado com a fotossíntese, desenvolvimento e atividades das raízes, absorção iônica de nutrientes, crescimento e diferenciação celular. Os íons amônio $\left(\mathrm{NH}_{4}^{+}\right)$ou nitrato $\left(\mathrm{NO}_{3}{ }^{-}\right)$são as principais formas de absorção de $\mathrm{N}$ pelas plantas, por isso, a aplicação de proporções desbalanceadas pode provocar alteração no crescimento da planta (MAJEROWICZ et al., 2000).

Dada à importância da espécie e a alta mobilidade do nitrogênio no solo, é de elevada importância o desenvolvimento de estudos que permitam maximizar a eficiência do uso desse nutriente. Dessa forma, o presente trabalho teve como objetivo avaliar o efeito de proporções de $\mathrm{NO}_{3}{ }^{-}: \mathrm{NH}_{4}{ }^{+}$em solução nutritiva no crescimento e de P. angulata.

\section{MATERIAL E MÉTODOS}

O trabalho foi conduzido na Unidade Experimental Horto Florestal da Universidade Estadual de Feira de Santana (UEFS), Feira de Santana, Bahia. As sementes de $P$. angulata foram colocadas para germinar em bandejas com substrato comercial sob irrigação diária, mantendo-as sempre úmidas. Vinte dias após a germinação, as mudas foram transplantadas para o sistema hidropônico tipo floating, em vasos individuais. Foi utilizada a solução de Sarruge (1975) modificada para o cultivo de $P$. angulata, com o uso da dose de $162 \mathrm{mg} . \mathrm{L}^{-1}$ de nitrogênio. 
O delineamento utilizado foi o inteiramente casualizado, com quatro tratamentos e seis repetições. Os tratamentos consistiram em quatro proporções de $\mathrm{NO}_{3}{ }^{-}: \mathrm{NH}_{4}{ }^{+}$ $(100: 0 ; 75: 25 ; 50: 50,25: 75)$. As avaliações foram realizadas 45 dias após o transplante para o sistema hidropônico. Foi determinada a altura da planta (ALT) e o diâmetro do caule (DC). A área foliar (AF) foi mensurada com um integrador de área foliar (Li-Cor, modelo Li-3100C). Em seguida, os materiais vegetais foram acondicionados em sacos de papel, e transferidos para estufa com circulação forçada de ar para determinação massa seca da raiz (MSR) e a massa seca da parte aérea (MSPA). Posteriormente, calculou-se a relação raiz/parte aérea (RAIZ/PA) e a área foliar específica (AFE).

A determinação do teor de clorofila total foi realizada utilizando discos foliares de área conhecida que foram imediatamente imersos em $5 \mathrm{~mL}$ álcool 95\%, segundo Tanan et al. (2017). Os tubos foram vedados e envoltos em papel alumínio, e após 24 horas foram realizadas as leituras em espectrofotômetro, nas absorbâncias de 664,2 e $648,6 \mathrm{~nm}$, e as concentrações calculadas de acordo com as equações propostas por Lichtenthaler (1987). Os dados obtidos foram submetidos à análise da variância e teste Tukey utilizando o programa estatístico SISVAR® 5.3 (FERREIRA, 2008).

\section{RESULTADOS E DISCUSSÃO}

As variáveis de crescimento não diferiram estatisticamente para as proporções de $\mathrm{NO}_{3}{ }^{-}: \mathrm{NH}_{4}{ }^{+}$de 100:0; 75:25 e 50:50 (Tabela 1 ), exceto para a (RAIZ/PA) no qual o tratamento 50:50 foi inferior aos demais (Tabela 1), demonstrando que as plantas obtiveram desempenho regular quando adicionados até $50 \%$ de amônio na solução nutritiva. Segundo Oliveira et al. (2007), os tratamentos com $\mathrm{NO}_{3}{ }^{-}: \mathrm{NH}_{4}{ }^{+}$balanceados disponibilizam mais $\mathrm{N}$, o que pode elevar a produtividade das culturas.

A maior proporção de amônio utilizada proporcionou redução em todos os caracteres avaliados em comparação aos demais tratamentos, indicando uma preferência de absorção do nitrogênio na forma nítrica pelas plantas de $P$. angulata. Foi verificada a redução de $18,36 \%$ e $14,71 \%$ na altura e diâmetro do caule, respectivamente, no tratamento com maior proporção de amônio quando comparada com o tratamento sem adição de amônio (Tabela 1), o que pode estar relacionado a toxidez do $\mathrm{NH}_{4}{ }^{+}$em células vegetais, onde atua como desacoplador entre o fluxo de elétrons, fosforilação oxidativa e a fotofosforilação (TAIZ et al., 2017).

Tabela 1: Médias das variáveis de crescimento de plantas de $P$. angulata cultivadas em diferentes proporções de nitrato e amônio, Feira de Santana-Ba, 2018.

\begin{tabular}{|c|c|c|c|c|c|}
\hline & \multicolumn{4}{|c|}{ PROPORÇÕES NO${ }_{3}^{-}: \mathrm{NH}_{4}{ }^{+}$} & \multirow[b]{2}{*}{ CV\% } \\
\hline & 100:0 & $75: 25$ & $50: 50$ & $25: 75$ & \\
\hline ALT (m) & $16,66 \mathrm{ab}$ & $18,36 \mathrm{a}$ & $15,33 \mathrm{ab}$ & $13,61 \mathrm{c}$ & 20,20 \\
\hline DC (mm) & $17,06 \mathrm{a}$ & $16,88 \mathrm{a}$ & $15,55 \mathrm{ab}$ & $14,55 b$ & 9,82 \\
\hline $\operatorname{MSR}(\mathbf{g})$ & $2,96 \mathrm{a}$ & $2,6233 a$ & $2,0411 \mathrm{ab}$ & $1,3433 b$ & 35,49 \\
\hline $\operatorname{MSPA}(\mathbf{g})$ & $24,3355 a$ & $24,9655 \mathrm{a}$ & $21,6466 a$ & $9,9155 b$ & 29,52 \\
\hline RAIZ/PA & $0,12 \mathrm{ab}$ & $0,1033 b c$ & $0,0922 \mathrm{c}$ & $0,1366 a$ & 19,02 \\
\hline $\mathbf{A F}\left(\mathbf{m}^{2}\right)$ & $4617,45 a$ & $5712,25 \mathrm{a}$ & $4769,45 a$ & $1886,81 b$ & 30,57 \\
\hline AFE & $591,39 \mathrm{ab}$ & $712,44 a$ & $674,41 \mathrm{a}$ & $504,24 \mathrm{~b}$ & 18,77 \\
\hline
\end{tabular}

Médias seguidas de mesma letra, na linha, não se diferenciam pelo teste Tukey ( $\mathrm{p} \leq 5 \%$ ). $(\mathrm{ALT})=$ altura de plantas; $(\mathrm{DC})=$ diâmetro do caule; $(\mathrm{MSR})=$ massa seca de raiz; MSPA = massa seca da parta aérea; RAIZ/PA = relação raiz/parte aérea; AF = área foliar; $(\mathrm{AFE})=$ área foliar específica.

As maiores médias para AF foram obtidas quando utilizados $25 \%$ e $50 \%$ de amônio na solução nutritiva, apesar destes não diferirem do tratamento somente com a 
aplicação de nitrato. A maior proporção de amônio promoveu redução na área foliar $(59,14 \%)$ quando comparada com o tratamento 100:00, afetando diretamente o processo de fotossíntese, pois ocasionou menor área fotossinteticamente ativa. $\mathrm{O}$ nitrogênio é o principal nutriente que influencia a área foliar $\mathrm{e}$, consequentemente, na taxa fotossintética, promovendo maior acúmulo de massa seca nas plantas (MARSCHNER, 2012). Quando a fonte nitrogenada não é adequada, as plantas têm a absorção comprometida, apresentando desempenho semelhante ao déficit desse elemento.

Não foram observadas diferenças para a AFE entre os tratamentos com concentração de até $50 \%$ de amônio, mas demonstrou acréscimo significativo quando comparado ao tratamento com maior porcentagem de amônio (75\%). O aumento da AFE geralmente implica na redução da espessura da folha (LAMBERS et al., 1998), ocasionando uma redução na biomassa das folhas e consequentemente a produtividade da planta.

O valor de MSPA obtido foi inferior no tratamento com predomínio da fonte amoniacal. O amônio pode ter ação negativa sobre a condutância estomática da planta, interferindo diretamente na transpiração e fotossíntese e assim comprometendo o crescimento (SILVA et al., 2010), e esse menor incremento da MSPA refletiu na maior relação RAIZ/PA obtida no tratamento com $75 \%$ de amônio (Tabela 1).

$\mathrm{O}$ teor de clorofila total das plantas sofreu influência significativa $(\mathrm{P}<0,05)$ dos tratamentos aplicados (Figura 1). O tratamento na proporção 100:0 mesmo não diferindo estatisticamente dos tratamentos com 50:50 e 25:75, foi o que apresentou menor teor de clorofila nas folhas de $P$. angulata, isso possivelmente aconteceu pela senescência precoce das plantas deste tratamento, causada pela acidificação da solução, e assim, fazendo com que tenha cessado a absorção de nutrientes. Raab \& Terry (1994), diz que a acidificação do meio provocada pela liberação de íons $\mathrm{H}^{+}$faz com que cesse a absorção de muitos nutrientes, inclusive nitrogênio, que está presente na composição da molécula de clorofila.

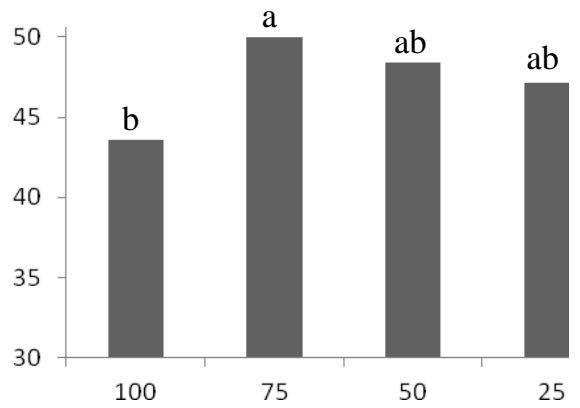

Figura 1: Médias de valores do teor de clorofila total de plantas de P. angulata cultivadas em diferentes proporções de nitrato e amônio, Feira de Santana-Ba, 2018.

As plantas ao serem submetidas aos tratamentos com duas formas iônicas apresentaram maior teor de clorofila, mostrando assim que, as plantas respondem de maneira negativa ao suprimento de apenas uma forma de absorção de $\mathrm{N}$ quanto ao teor de clorofila. Segundo Lewis et al. (1982), melhores resultados são encontrados nas produções com a utilização das duas formas de $\mathrm{N}$ na solução, e que se mostram superiores ao uso de apenas uma delas.

\section{CONCLUSÕES}

O crescimento das plantas de Physalis angulata é influenciado pela proporção de nitrato:amônio na solução nutritiva, podendo utilizar até 50\% de amônio.

O fornecimento de nitrogênio na proporção de nitrato:amônio de 25:75 na solução nutritiva reduz o crescimento das plantas de Physalis angulata. 


\section{REFERÊNCIAS}

FERREIRA, D. F. 2008. SISVAR: Um programa para analises e ensino de estatística.

Revista Científica Symposium,v. 6, p. 36-41.

HARBORNE, J. B.; WILLIAMS, C. A. 2000. Advances in flavonoid research since 1992. Phytochemistry, v. 55, n. 6, p. 481-504.

LACERDA, C. F.; FILHO, J. E.; PINHEIRO C.B. 2007. Fisiologia Vegetal. Universidade Federal do Ceará. Fortaleza. Disponível em <http://www.fisiologiavegetal.ufc.br/apostila.htm> Acesso em: 30 julho 2018.

LAMBERS, H.; CHAPIM III, F.S.; PONS, T.L. 1998. Plant physiological ecology. New York: Springer. 540p.

LICHTENTHALER, H. K. 1987. Chlorophylls and carotenoids: Pigments of photosynthetic biomembranes. Methods Enzymology, 148, 350-382.

LEWIS, O.A.M.; JAMES, D.M. \& HEWITT, E.J. 1982. Nitrogen assimilation in barley (Hordeum vulgare L. cv. Mazurka) in response to nitrate and ammonium nutrition. Annal of Botany, London,49:39-49.

MAJEROWICZ, N., Kerbauy, G. B., Nievola, C. C. and Suzuki, R. M. 2000. Growth and nitrogen metabolism of Catasetumfimbriatum (Orchidaceae) grown with different nitrogen sources. Environ. Exp. Bot. v.44, p.195-206.

MARSCHNER, P. 2012. Marschner's mineral nutrition of higher plants. 3. ed. San Diego: Academic Press. 672 p.

OLIVEIRA, L. A.; KORNDÖRFER, G.H.; PEREIRA, A.C. 2007. Acumulação de silício em arroz em diferentes condições de $\mathrm{pH}$ da rizosfera. Revista Brasileira de Ciência do Solo, Viçosa, v.31, n.4, p.685-690.

RAAB, T.K.; TERRY, N. 1994. Nitrogen-source regulation of growth and photosynthesis in Beta vulgaris L. Plant Physiology, Bethesda, v.105, p.1159-1166.

SARRUGE, J. R. 1975. Soluções nutritivas. Summa Phytopathologica, Botucatu, v. 1, n. 3, p. 231-233.

SILVA, P. C. C.; COUTO, J. L.; SANTOS, SANOS, A. R. 2010. Efeito dos íons amônio e nitrato no desenvolvimento do girassol em solução nutritiva. Revista da Faculdade de Zootecnia, Veterinária e Agronomia, Uruguaiana, v.17, n.1, p. 104114.

TANAN, T. T.; NASCIMENTO, M. N.; LEITE, R. S.; GUIMARÃES, D. S. 2017. Spectrophotometric Determinations of Chloroplastidic Pigments in Physalis angulata L. Leaves Using Different Methodologies. Journal of Agricultural Science; Vol. 9, No. 11.

TAIZ, L.; ZEIGER, E.; MOLLER, I.M. MOLLER, I. M.; MURPHY, A. 2017. Fisiologia e desenvolvimento vegetal. 6. ed. Porto Alegre: Artmed. 